\title{
Effects of Uninephrectomy on Electrical Properties of the Cortical Collecting Duct from Rabbit Remnant Kidneys
}

\author{
Satoru Ebata, Shigeaki Muto, and Yasushi Asano \\ Department of Nephrology, Jichi Medical School, Minamikawachi, Kawachi, Tochigi, 329-04 Japan
}

\begin{abstract}
Microelectrode techniques were used to determine the $\mathrm{Na}^{+}$and $\mathrm{K}^{+}$transport properties of the collecting duct cell in the isolated cortical collecting duct (CCD) from rabbits $14 \mathrm{~d}$ after uninephrectomy (UNX); results were compared with those from sham-operated rabbits (control). UNX had no effects on plasma aldosterone levels. The CCDs from UNX rabbits exhibited structural hypertrophy. The lumen negative transepithelial voltage and the basolateral membrane voltage $\left(V_{B}\right)$ were elevated in the UNX group. Although the transepithelial conductance $\left(G_{\mathrm{T}}\right)$ and the fractional apical membrane resistance $\left(f R_{A}\right)$ were not different between the two groups, the conductances of the apical and the basolateral membranes were increased, and the tight junction conductance was decreased in the UNX group. The amiloride-sensitive changes in apical membrane voltage $\left(V_{\mathrm{A}}\right), f R_{\mathrm{A}}$, and $G_{\mathrm{T}}$ were greater in the UNX group. The changes in $V_{A}$ upon raising the perfusate $\mathrm{K}^{+}$ concentration and the changes in $V_{A}$ and $G_{\mathrm{T}}$ upon addition of $\mathrm{Ba}^{2+}$ to the perfusate were elevated in the UNX group. Upon raising $\mathrm{K}^{+}$in the bath, a large depolarization of $V_{B}$ was observed in the $\mathrm{UNX}$ group. Lowering the bath $\mathrm{Cl}^{-}$resulted in a small depolarization of $V_{\mathrm{B}}$ in the UNX group. Addition of $\mathrm{Ba}^{2+}$ to the bath in the UNX group caused the $V_{B}$ to hyperpolarize in parallel with decreases in $G_{\mathrm{T}}$ and $f R_{\mathrm{A}}$ whereas in the control group it had no effect on $V_{B}$. Addition of ouabain to the bath resulted in a large depolarization of $V_{B}$ in the UNX group. We conclude that (a) UNX stimulates conductances of $\mathrm{Na}^{+}$and $\mathrm{K}^{+}$ in the apical membrane, active $\mathrm{Na}^{+}-\mathrm{K}^{+}$pump activity, and $\mathrm{K}^{+}$ conductance in the basolateral membrane, independently of plasma aldosterone; $(b)$ The basolateral membrane in the tubules of UNX rabbits is more selective to $\mathrm{K}^{+}$; and (c) the hyperpolarization of $V_{B}$ upon UNX may increase passive $\mathrm{K}^{+}$entry into the cell across the basolateral membrane. ( J. Clin. Invest. 1992. 90:1547-1557.) Key words: electrophysiology • distal delivery of sodium • sodium conductance $\bullet$ potassium conductance - sodium pump
\end{abstract}

Portions of this work have been published in abstract form (1991. FASEB [Fed. Am. Soc. Exp. Biol.] J. 5:739A).

Address correspondence to Shigeaki Muto, M. D., Department of Nephrology, Jichi Medical School, Minamikawachi, Tochigi 329-04, Japan.

Received for publication 21 October 1991 and in revised form 13 May 1992.

J. Clin. Invest.

(C) The American Society for Clinical Investigation, Inc.

$0021-9738 / 92 / 10 / 1547 / 11 \quad \$ 2.00$

Volume 90, October 1992, 1547-1557

\section{Introduction}

After loss of renal mass, the remaining nephrons, including the cortical collecting duct (CCD), ${ }^{1}$ undergo a compensatory hypertrophy and an adaptation that maintains water, electrolytes, and acid-base balance (1-3). For electrolyte balance, previous studies of the CCDs of remnant kidneys after nephrectomy exhibited adaptive increase in $\mathrm{Na}^{+}$reabsorption (4) and $\mathrm{K}^{+}$ secretion (5). These adaptive changes also included an increase in $\mathrm{Na}^{+} / \mathrm{K}^{+}$ATPase activity $(6,7)$ and an amplification of the basolateral membrane area of the collecting duct $(C D)$ cell $(8)$. These findings suggest that the $\mathrm{CD}$ cell, which is mainly responsible for $\mathrm{Na}^{+}$and $\mathrm{K}^{+}$transports in the CCD (9-16), would play the key role in the adaptation after reduction of renal mass. However, the cellular mechanisms of these adaptive changes remain unknown. The purpose of the present study was to determine the electrical properties in the apical as well as the basolateral membranes of the CD cell in the CCD from uninephrectomized rabbits.

Chronic elevations in aldosterone levels are also known to stimulate the proliferation of the basolateral membrane area of the $\mathrm{CD}$ cell $(17)$, to enhance $\mathrm{Na}^{+} / \mathrm{K}^{+}$ATPase activity $(18,19)$ and to increase the $\mathrm{Na}^{+}$and $\mathrm{K}^{+}$transport capacity in the CCD $(11,16,20,21)$. Thus, elevated aldosterone levels would induce the functional and morphological adaptations in the CCD from remnant kidneys after nephrectomy. Therefore, we also determined whether the changes in plasma aldosterone contribute to the adaptations in the CCD after a reduction of renal mass.

The present study demonstrates that uninephrectomy stimulates conductances of $\mathrm{Na}^{+}$and $\mathrm{K}^{+}$in the apical membrane, active $\mathrm{Na}^{+} / \mathrm{K}^{+}$ATPase pump activity, and $\mathrm{K}^{+}$conductance in the basolateral membrane, independently of plasma aldosterone. These functional adaptive changes are associated with structural hypertrophy in the CCD from remnant kidneys.

\section{Methods}

Animals and surgical procedures. Female Japanese white rabbits were used for all experiments. After a period of acclimation, the rabbits were divided into two groups: sham operation (control) and uninephrec-

1. Abbreviations used in this paper: $\mathrm{CCD}$, cortical collecting duct; $\mathrm{CD}$ cell, collecting duct cell; $E_{B}^{K}$, Nernst equilibrium potential for $\mathrm{K}^{+}$ across the basolateral membrane; $\triangle \mathrm{EMF}$, change in basolateral electromotive force due to ion substitution; $f R_{\mathrm{A}}$, fractional apical membrane resistance; $G_{\mathrm{A}}$, apical membrane conductance; $G_{\mathrm{B}}$, basolateral membrane conductance; $G_{\mathrm{T}}$, transepithelial conductance; $G_{\mathrm{Tj}}$, tight junction conductance; uninephrectomy, UNX; $V_{\mathrm{A}}$, apical membrane voltage; $V_{\mathrm{B}}$, basolateral membrane voltage; $V_{\mathrm{T}}$, transepithelial voltage. 
tomy (UNX). The operative procedures were as follows: First, all the animals were anesthetized with sodium pentobarbital $(30 \mathrm{mg} / \mathrm{kg}$, i.v.). Second, the abdomen of each animal was opened by a left flank incision. After the abdomen was opened, the left kidney of those in the UNX group was removed via a dorsolateral incision under sterile conditions. The kidney was separated from the adrenal gland and from the associated connective tissue, the renal blood vessels were ligated, and the organ was excised. Then, the abdominal musculature in both groups of animals was sewn. The rabbits from two groups were maintained on standard rabbit chow (rabbit chow, Clea Japan, Inc., Tokyo, Japan), containing $\mathrm{Na}^{+}$of $120 \mathrm{meq} / \mathrm{kg}$ diet and $\mathrm{K}^{+}$of $400 \mathrm{meq} / \mathrm{kg}$ diet, and tap water ad lib.

Metabolic balance studies. Balance studies were performed on two groups of animals. On the 14th day after surgery, they were individually placed in the metabolic cages for $24 \mathrm{~h}$. During these periods, $\mathrm{Na}^{+}$, $\mathrm{K}^{+}, \mathrm{Cl}^{-}$, and creatinine concentrations in the plasma and in the urine were measured. Also, the urine volume for $24 \mathrm{~h}$ was determined gravimetrically. The GFR was measured in terms of the endogenous creatinine clearance. The creatinine clearance was calculated by standard formulas using urine/plasma concentration ratios and urine flows.

Isolation and perfusion of tubules. On the 15 th day after surgical procedure, the animals of both groups were anesthetized with sodium pentobarbital $(35 \mathrm{mg} / \mathrm{kg}$, i.v.), the right kidney was removed and weighed. Slices of the coronary section 1-2-mm thick were made and transferred to a dish containing a cold intracellular fluid-like solution of the following composition ( $\mathrm{mM}$ ): $14 \mathrm{KCl}, 44 \mathrm{~K}_{2} \mathrm{HPO}_{4}, 14 \mathrm{KH}_{2} \mathrm{PO}_{4}$, $9 \mathrm{NaHCO}_{3}$, and 160 sucrose. The CCD segments were isolated and perfused in vitro according to the method of Burg et al. (22) with slight modifications in this laboratory $(13,14)$. Briefly, the tubule segment was perfused via a perfusion pipette inserted into one end of the tubule. A PE-10 tube (Intramedic; Clay Adams, Parsippany, NJ) was inserted into the perfusion pipette to permit rapid exchange of the perfusate with a test solution within $5 \mathrm{~s}$. The opposite or distal end of the tubule was held in a glass holding pipette with a small amount of Sylgard 184 (Dow Corning Corp., Midland, MI). The perfusion flow rates were $>20 \mathrm{nl} / \mathrm{min}$ and controlled by the height of the outflow sink. The tubule was perfused in the bathing chamber of $\sim 100 \mu$ l to permit rapid exchange of the bathing solution within $5 \mathrm{~s}$. The bathing solution flowed at $5-15 \mathrm{ml} / \mathrm{min}$ from the reservoirs by gravity through a water jacket to permit the bath temperature to be regulated at $37^{\circ} \mathrm{C}$.

Electrical measurements. The transepithelial and cellular electrical properties of the tubule were measured using techniques described previously by Muto et al. $(13,14,16)$. In brief, the transepithelial voltage $\left(V_{\mathrm{T}}\right)$ was measured through the perfusion pipette, which was connected to one channel of a dual-channel electrometer (Duo 773; W-P Instruments, Inc., New Haven, CT) with a $3 \mathrm{M} \mathrm{KCl}-3 \%$ agar bridge and a calomel half-cell electrode. The basolateral membrane voltage $\left(V_{\mathrm{B}}\right)$ was measured with $0.5 \mathrm{M} \mathrm{KCl}$-filled microelectrodes, which were fabricated from borosilicate glass capillaries (GD-1.5; $1.5 \mathrm{~mm}$ OD, 1.0 mm ID; Narishige Scientific Laboratory, Tokyo, Japan) by using a vertical puller (PE-2; Narishige Scientific Laboratory). Both voltages were referenced to the bath and were recorded on a four-pen chart recorder (R64; Rikadenki, Tokyo, Japan). Cable analysis was used to calculate the transepithelial conductance $\left(G_{\mathrm{T}}\right)$, and the fractional apical membrane resistance $\left(f R_{\mathrm{A}}\right)$ as described in detail previously $(9,10$, 13-16). Constant-current pulses, $50 \mathrm{nA}$ ( $300 \mathrm{~ms}$ in duration, 10-s interval), were injected into the tubule lumen via the perfusion pipette. The $f R_{\mathrm{A}}$ was calculated from the deflection of the apical membrane voltage $\left(V_{\mathrm{A}}\right)$ with current passage, divided by the change in the $V_{\mathrm{T}}$ calculated for the point of impalement.

The basolateral, apical, and tight junction conductances $\left(G_{\mathrm{B}}, G_{\mathrm{A}}\right.$, and $G_{\mathrm{Tj}}$, respectively) were estimated using $2 \mathrm{mM} \mathrm{Ba}^{2+}$ as a probe to the equation described previously by O'Neil and Sansom (10) and Muto et al. (16): $G_{\mathrm{T}}=\left(1-f R_{\mathrm{A}}\right) G_{\mathrm{B}}+G_{\mathrm{Tj}}$.

Ion substitution studies were conducted to determine the relative ion permselectivity of the basolateral membrane. When the ion concentration of the bathing solutions was changed, the initial peak change of $V_{\mathrm{B}}$ was used with fast bath exchange rates $(2-5 \mathrm{~s})$ to minimize sec- ondary effects such as changes in cellular ion activities. Voltage changes due to lowering bath $\mathrm{Cl}^{-}$and raising bath $\mathrm{K}^{+}$concentrations were corrected for liquid junction potentials with free-flowing $3 \mathrm{M} \mathrm{KCl}$ electrodes. The change in basolateral membrane electromotive force due to ion substitution ( $\triangle E M F$ ) was estimated according to the following equation: $\Delta E M F=\Delta V_{\mathrm{B}}-I \cdot R_{\mathrm{B}}$ where $\Delta V_{\mathrm{B}}$ is the measured change in $V_{\mathrm{B}}$ due to ion substitution and $I \cdot R_{\mathrm{B}}$ is the change in membrane potential due to the dissipation of energy from current flowing across the basolateral membrane resistance. The circular loop current $(I)$ was then estimated from $G_{\mathrm{T} j}$ and the change in $V_{\mathrm{T}}$ on ion substitution $\left(\Delta V_{\mathrm{T}}\right)$ as $I=G_{\mathrm{T} j} \cdot \Delta V_{\mathrm{T}}$.

Identification of $C D$ cells. Electrical identification of $\mathrm{CD}$ cells was performed according to the criteria described previously by Muto et al. (13-16). CD cells have a relatively lower $f R_{\mathrm{A}}$; higher $V_{\mathrm{B}}$, apical $\mathrm{Na}^{+}$, and $\mathrm{K}^{+}$conductances; and basolateral $\mathrm{K}^{+}$and $\mathrm{Cl}^{-}$conductances.

Solutions and materials. The composition of the control bathing and perfusing solution was as follows $(\mathrm{mM}): 110 \mathrm{NaCl}, 5 \mathrm{KCl}, 1$ $\mathrm{MgCl}_{2}, 1.8 \mathrm{CaCl}_{2}, 25 \mathrm{NaHCO}_{3}, 10 \mathrm{Na}$ acetate, $0.8 \mathrm{Na}_{2} \mathrm{HPO}_{4}, 0.2$ $\mathrm{NaH}_{2} \mathrm{PO}_{4}, 5 \mathrm{~L}$-alanine, and $8.3 \mathrm{D}$-glucose. This control solution had an osmolality between 285 and $295 \mathrm{mosmol} / \mathrm{kg} / \mathrm{H}_{2} \mathrm{O}$, and was equilibrated with $95 \% \mathrm{O}_{2} / 5 \% \mathrm{CO}_{2}$ and adjusted to $\mathrm{pH} 7.4$ at $37^{\circ} \mathrm{C}$. In some experiments, $45 \mathrm{mM} \mathrm{Na}^{+}$was replaced with $\mathrm{K}^{+}$, or $108.6 \mathrm{~m} \mathrm{M} \mathrm{Cl}^{-}$was replaced with cyclamate.

Amiloride (Sigma Chemical Co., St. Louis, MO) was added to the luminal perfusate to achieve a final concentration of $50 \mu \mathrm{M}$. Ouabain (Sigma Chemical Co.) was used in the bath at a concentration of $10^{-4}$ M. $\mathrm{BaCl}_{2}$ was used at a final concentration of $2 \mathrm{mM}$.

Tubular measurements. Tubular lengths were measured at the end of each experiment with a calibrated reticle in the eyepiece of the microscope. The tubules were photographed during perfusion at a proximal, central, and distal site at a magnification of 200 . Inner and outer diameters were measured at 0.05 - $\mathrm{mm}$ intervals along the tubule. Reported values are the average of at least five measurements. Since the tubules from both groups were rapidly perfused at similar rates and pressures, the degree of distention of the lumen is assumed to be similar in all.

Radioimmunoassay for plasma aldosterone. At $16 \mathrm{~h}$ and 7 and $14 \mathrm{~d}$ after the surgery, blood was also taken from control and UNX rabbits. Specific radioimmunoassay (SPAC-S Aldosterone Kit; Daiichi Radio Isotope Labs, Tokyo, Japan ) was used to measure the plasma aldosterone concentration.

Statistics. The data are expressed as mean \pm SE. Differences between groups were determined by the Student's $t$ test for either paired or nonpaired data as appropriate. $P$ values $<0.05$ were considered significant.

\section{Results}

\section{Effects of UNX on body and kidney weights}

Body and kidney weights in control and UNX animals are given in Table I. UNX had no adverse effects on body growth as UNX rabbits attained the same weight at $14 \mathrm{~d}$ as did control

Table I. Effects of Uninephrectomy on Body and Kidney Weights

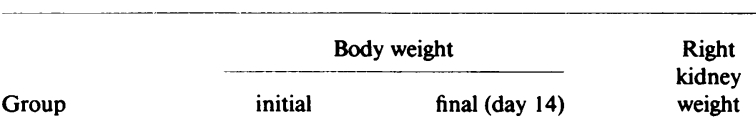

$\begin{array}{lccc}\text { Control }(n=20) & 1.99 \pm 0.04 & 2.32 \pm 0.04 & 7.5 \pm 0.3 \\ \text { UNX }(n=24) & 1.97 \pm 0.04 & 2.23 \pm 0.04 & 11.3 \pm 0.4 \\ P & \text { NS } & \text { NS } & <0.005\end{array}$

Values are mean \pm SE. $n$, number of animals. 
Table II. Metabolic Balance in Control and UNX Rabbits

\begin{tabular}{|c|c|c|c|c|c|c|c|c|c|}
\hline \multirow[b]{2}{*}{ Group } & \multicolumn{4}{|c|}{ Plasma } & \multirow{2}{*}{$\begin{array}{l}\text { Urine } \\
\text { volume }\end{array}$} & \multicolumn{4}{|c|}{ Daily urinary excretion } \\
\hline & $\mathrm{Na}$ & K & $\mathrm{Cl}$ & $\mathrm{Cr}$ & & $\mathrm{Na}$ & $\mathrm{K}$ & $\mathrm{Cl}$ & $\mathrm{Cr}$ \\
\hline & meq/liter & meq/liter & meq/liter & $m g / d l$ & $m l / d$ & $m e q / d$ & $m e q / d$ & $m e q / d$ & $m g / d$ \\
\hline Control $(n=13)$ & $138.4 \pm 0.9$ & $4.3 \pm 0.1$ & $97.5 \pm 0.8$ & $0.9 \pm 0.1$ & $163.6 \pm 16.9$ & $9.2 \pm 2.5$ & $39.1 \pm 4.6$ & $15.8 \pm 2.3$ & $103.8 \pm 11.9$ \\
\hline $\mathrm{UNX}(n=11)$ & $137.8 \pm 1.6$ & $4.3 \pm 0.2$ & $97.8 \pm 1.4$ & $0.9 \pm 0.1$ & $172.5 \pm 19.6$ & $9.5 \pm 1.2$ & $40.0 \pm 5.7$ & $16.2 \pm 2.6$ & $99.2 \pm 16.7$ \\
\hline
\end{tabular}

Values are mean $\pm \mathrm{SE}$. Cr, creatinine; $n$, number of animals.

rabbits. The kidney growth, however, was significantly altered, with the remaining right kidney undergoing compensatory hypertrophy.

\section{Metabolic balance study}

Table II shows plasma electrolytes and creatinine concentrations and their daily urinary excretions in control and UNX rabbits. UNX had no significant effects on plasma creatinine concentration and its daily urinary excretion. In addition, there were also no significant differences of plasma levels of electrolytes and their daily urinary excretions between the two groups.

\section{Renal function}

$14 \mathrm{~d}$ after UNX, the GFR was significantly greater in the hypertrophied remaining kidney from the UNX rabbits $(8.2 \pm 1.5$ $\mathrm{ml} / \mathrm{min}$ per kidney, $n=11, P<0.025)$ than in the kidney from the control rabbits $(4.6 \pm 0.6 \mathrm{ml} / \mathrm{min}$ per kidney, $n=13)$. This increase was paralleled by both a significantly higher absolute sodium reabsorption rate $(1,127.3 \pm 201.6$ vs. $627.1 \pm 86.6 \mu \mathrm{eq} /$ min per kidney, $P<0.025)$ and a significantly higher absolute potassium excretion rate $(27.8 \pm 4.0$ vs. $13.6 \pm 1.6 \mu \mathrm{eq} / \mathrm{min}$ per kidney, $P<0.001$ ) in the hypertrophied remaining kidney. These findings are similar to those reported by Mujais and Kurzman ( 7 ) in the UNX rats $14 \mathrm{~d}$ after surgery.

\section{Electrophysiological data}

The length of the perfused tubule in the control and UNX groups was $1,007.2 \pm 48.2(n=32)$ and $1,052.8 \pm 81.0 \mu \mathrm{m}(n$ $=18$ ), respectively. On the other hand, both the inner and outer diameters of 18 tubules from UNX rabbits were significantly greater than those of 32 tubules from control rabbits (inner diameters: $33.0 \pm 1.1$ vs. $29.3 \pm 0.8 \mu \mathrm{m}, P<0.01$; outer diameters: $42.8 \pm 1.1$ vs. $39.1 \pm 0.7 \mu \mathrm{m}, P<0.01)$. These results
Figure 1. Potential profiles of $C D$ cells from CCDs of CONTROL and UNX rabbits. Values are mean $\pm \mathrm{SE}$. Number of experiments in each group was 24 . ${ }^{*} P<0.001$ compared with the control group. indicate the compensatory hypertrophy of CCDs from UNX rabbits. These findings are consistent with those reported by Vehaskari et al. (4), in the CCD from the remnant kidneys of the rabbits following surgical reduction of renal mass by $3 / 4$ to $7 / 8$.

Effects of $U N X$ on barrier voltages and conductances. The potential profiles of $C D$ cells of tubules of the two groups are illustrated in Fig. 1. The $V_{\mathrm{T}}$ and $V_{\mathrm{B}}$ of the tubules from UNX rabbits were significantly higher than those of the tubules from control rabbits. On the other hand, the calculated $V_{\mathrm{A}}$ was unchanged upon UNX (75.0 $\pm 1.8 \mathrm{mV}$ vs. $80.7 \pm 2.6 \mathrm{mV})$.

Table III shows the effects of UNX on $f R_{\mathrm{A}}$ and barrier conductances. The values of $f R_{\mathrm{A}}$ and $G_{\mathrm{T}}$ were not significantly different between the two groups. However, both $G_{\mathrm{A}}$ and $G_{\mathrm{B}}$ were significantly higher and $G_{\mathrm{T} j}$ was significantly lower in the UNX group.

Effects of UNX on electrical properties of the apical membrane. As described above, UNX produced a 2.5 -fold increase in $G_{\mathrm{A}}$. The first set of the studies was, therefore, designed to examine whether this increase in $G_{\mathrm{A}}$ is the result of a change in the $\mathrm{Na}^{+}$conductance and/or $\mathrm{K}^{+}$conductance in the apical membrane of the CD cell.

To examine whether a difference in $\mathrm{Na}^{+}$conductance of the apical membrane of the $\mathrm{CD}$ cell exists between the two groups, we added a $\mathrm{Na}^{+}$channel inhibitor, amiloride, to the perfusate and observed the barrier voltages and conductances. Typical tracings of $V_{\mathrm{T}}$ and $V_{\mathrm{B}}$ in the tubules of two groups upon addition of $50 \mu \mathrm{M}$ amiloride to the perfusate are illustrated in Fig. 2. The effects of luminal amiloride on barrier voltages and conductances in the two groups are summarized in Table IV. Upon addition of luminal amiloride, the $V_{\mathrm{T}}$ and the $V_{\mathrm{B}}$ in the tubules of both groups were rapidly depolarized, resulting in a significant hyperpolarization of $V_{\mathrm{A}}$. However, the amiloridesensitive changes in $V_{\mathrm{A}}$ were significantly greater in the UNX

Table III. Effects of Uninephrectomy on Fractional Apical Membrane Resistance and Barrier Conductances

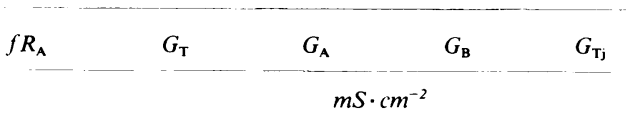

\begin{tabular}{|c|c|c|c|c|c|}
\hline $\begin{array}{l}\text { Control } \\
\qquad(n=12)\end{array}$ & $0.38 \pm 0.03$ & $8.7 \pm 0.6$ & $13.4 \pm 2.1$ & $7.8 \pm 1.2$ & $4.0 \pm 0.4$ \\
\hline \multicolumn{6}{|l|}{ UNX } \\
\hline$(n=17)$ & $0.34 \pm 0.04$ & $10.8 \pm 0.8$ & $33.9 \pm 5.9$ & $13.0 \pm 1.4$ & $2.7 \pm 0.3$ \\
\hline$P$ & NS & NS & $<0.01$ & $<0.05$ & $<0.05$ \\
\hline
\end{tabular}




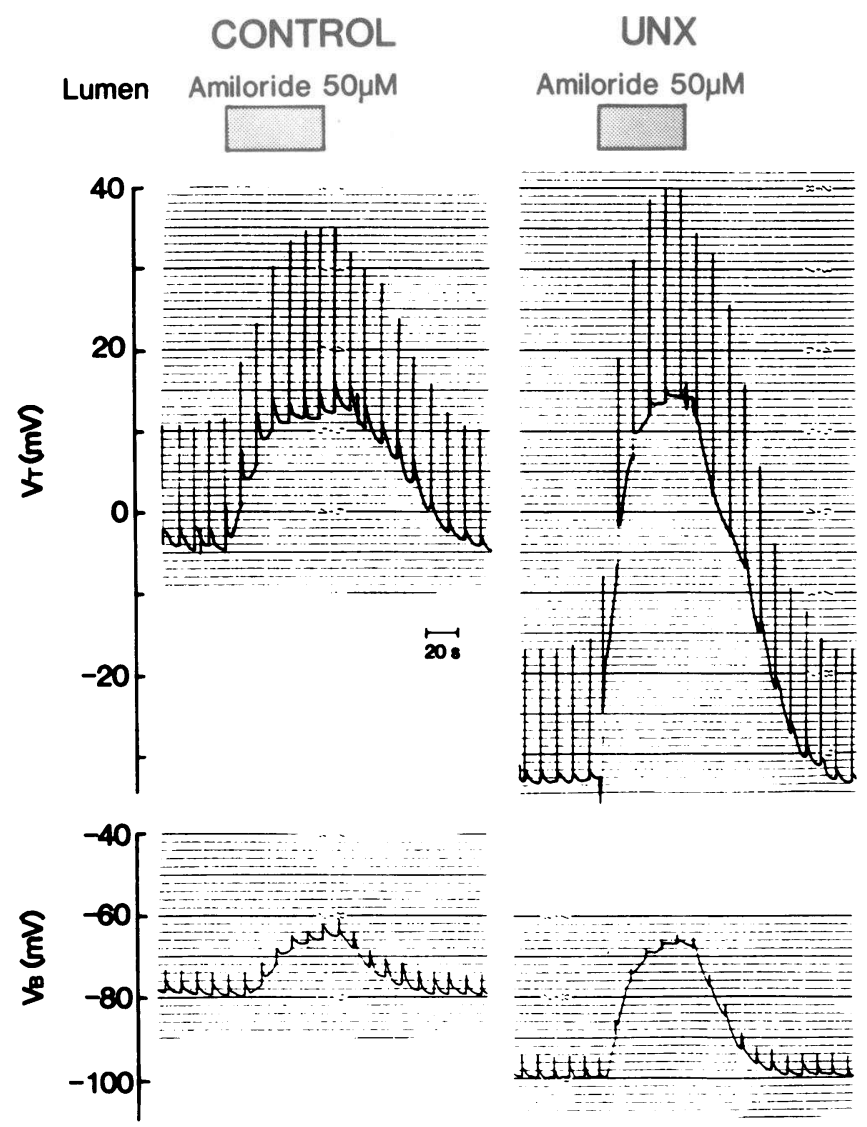

Figure 2. Typical tracings of $V_{\mathrm{T}}$ and $V_{\mathrm{B}}$ upon addition of $50 \mu \mathrm{M}$ amiloride to the perfusate in the tubules of CONTROL and UNX groups.

group. When the amiloride was added to the luminal perfusate in the tubules of the control group, the $G_{\mathrm{T}}$ was significantly decreased, and the $f R_{\mathrm{A}}$ was significantly increased. Although a similar pattern of the responses of $G_{\mathrm{T}}$ and $f R_{\mathrm{A}}$ was also observed in the tubules of the UNX group, the changes in $G_{\mathrm{T}}$ and $f R_{\mathrm{A}}$ were significantly greater. Taken together, these results indicate that the amiloride-sensitive $\mathrm{Na}^{+}$conductance in the apical membrane of the CD cell from UNX rabbits is significantly elevated.
The next set of studies was designed to examine whether the apical membrane $\mathrm{K}^{+}$conductance of the $\mathrm{CD}$ cell in the tubules from UNX rabbits is increased. We compared the electrical properties between the two groups upon raising the perfusate $\mathrm{K}^{+}$concentration from 5 to $50 \mathrm{mM}$. Typical tracings of $V_{\mathrm{T}}$ and $V_{\mathrm{B}}$ in the tubules of both groups are illustrated in Fig. 3. The effects of raising the perfusate $\mathrm{K}^{+}$concentration on barrier voltages and conductances at the initial peak response are summarized in Table $\mathrm{V}$. When the perfusate $\mathrm{K}^{+}$concentration was increased in the tubules of both groups, the lumen-negative $V_{\mathbf{T}}$ was rapidly increased within several seconds and was then slowly decreased. The $V_{\mathrm{B}}$ was also rapidly depolarized within several seconds and was then slowly further depolarized to a new steady state. During this fast phase, the $V_{\mathrm{A}}$ was rapidly depolarized in both groups. However, the initial peak changes in $V_{\mathrm{A}}$ were significantly greater in the UNX group. Upon raising the luminal perfusate $\mathrm{K}^{+}$concentration in the tubules of the control group, the $G_{\mathrm{T}}$ was significantly increased and the $f R_{\mathrm{A}}$ was significantly decreased. Similar pattern of the responses of $G_{\mathrm{T}}$ and $f R_{\mathrm{A}}$ was also observed in the tubules of the UNX group. However, the changes in $G_{\mathrm{T}}$ were greater in the UNX group. These results indicate that the apical membrane $\mathrm{K}^{+}$conductance is also increased upon UNX.

To further characterize the apical membrane $\mathrm{K}^{+}$conductive property after nephrectomy, we added a $\mathrm{K}^{+}$channel inhibitor, $\mathrm{Ba}^{2+}$, to the perfusate, and observed the electrical properties. Typical tracings of $V_{\mathrm{T}}$ and $V_{\mathrm{B}}$ upon addition of luminal $\mathrm{Ba}^{2+}$ are illustrated in Fig. 4. The effects of $\mathrm{Ba}^{2+}$ to the perfusate on barrier voltages and conductances at the initial peak response are summarized in Table VI. When $2 \mathrm{mM} \mathrm{Ba}^{2+}$ was added to the perfusate in the tubules of both groups, the lumennegative $V_{\mathrm{T}}$ was rapidly increased and was then slowly decreased to a new steady state. The $V_{\mathrm{B}}$ was rapidly depolarized within several seconds and was then slowly depolarized further to a new steady state. These findings are compatible with those reported by Sansom and O'Neil (23) and Muto et al. (16) in CCDs from normal rabbits. This fast phase is considered to represent the initial block of apical membrane $\mathrm{K}^{+}$conductance and current $(16,23)$. During this fast phase, the $V_{\mathrm{A}}$ was rapidly depolarized in both groups. However, the initial peak changes in $V_{\mathrm{A}}$ were much greater in the UNX group. Upon addition of $\mathrm{Ba}^{2+}$ to the perfusate in the tubules of the control group, the $G_{\mathrm{T}}$

Table IV. Effects of $50 \mu \mathrm{M}$ Amiloride in the Lumen on Barrier Voltages and Conductances

\begin{tabular}{|c|c|c|c|c|c|}
\hline & $V_{\mathrm{T}}$ & $V_{\mathrm{B}}$ & $V_{\mathrm{A}}$ & $G_{\mathrm{T}}$ & $f R_{\mathrm{A}}$ \\
\hline & $m V$ & $m V$ & $m V$ & $\mathrm{mS} \cdot \mathrm{cm}^{-2}$ & \\
\hline \multicolumn{6}{|l|}{ Control } \\
\hline Without amiloride & $-7.6 \pm 1.4(18)$ & $-79.8 \pm 1.6(18)$ & $72.2 \pm 1.9(18)$ & $8.9 \pm 1.2(8)$ & $0.50 \pm 0.09(8)$ \\
\hline With amiloride & $5.4 \pm 1.2(18)$ & $-72.1 \pm 2.0(18)$ & $77.6 \pm 2.0(18)$ & $7.2 \pm 1.1(8)$ & $0.66 \pm 0.09(8)$ \\
\hline Difference & $13.0 \pm 1.4$ & $7.7 \pm 0.9$ & $5.3 \pm 0.9$ & $-1.4 \pm 0.4$ & $0.16 \pm 0.03$ \\
\hline$P$ & $<0.001$ & $<0.001$ & $<0.001$ & $<0.001$ & $<0.005$ \\
\hline \multicolumn{6}{|l|}{ UNX } \\
\hline Without amiloride & $-29.0 \pm 0.9(14)$ & $-101.1 \pm 1.9(14)$ & $72.0 \pm 1.7(14)$ & $10.4 \pm 0.9(11)$ & $0.44 \pm 0.05(11)$ \\
\hline With amiloride & $9.6 \pm 2.0(14)$ & $-71.5 \pm 2.3(14)$ & $81.1 \pm 1.4(14)$ & $6.5 \pm 0.3(11)$ & $0.72 \pm 0.02(11)$ \\
\hline Difference & $38.6 \pm 2.5^{*}$ & $29.3 \pm 2.5^{*}$ & $10.7 \pm 0.8^{*}$ & $-3.9 \pm 0.9^{* *}$ & $0.28 \pm 0.04^{* *}$ \\
\hline$P$ & $<0.001$ & $<0.001$ & $<0.001$ & $<0.005$ & $<0.001$ \\
\hline
\end{tabular}

Values are mean \pm SE. Numerals in parentheses indicate number of experiments. ${ }^{*} P<0.001$ vs. control; ${ }^{* *} P<0.05$. Data were obtained from the same experiments. 
Table V. Effects of Luminal $\mathrm{K}^{+}$Elevation from 5 to $50 \mathrm{mM}$ on Barrier Voltages and Conductances

\begin{tabular}{|c|c|c|c|c|c|}
\hline & $V_{\mathrm{T}}$ & $V_{\mathrm{B}}$ & $V_{\mathrm{A}}$ & $G_{\mathrm{T}}$ & $f R_{\mathrm{A}}$ \\
\hline & $m V$ & $m V$ & $m V$ & $\mathrm{mS} \cdot \mathrm{cm}^{-2}$ & \\
\hline \multicolumn{6}{|l|}{ Control } \\
\hline $\mathrm{K}^{+}, 5 \mathrm{mM}$ & $-6.3 \pm 0.9(22)$ & $-82.4 \pm 1.5(22)$ & $76.2 \pm 1.6(22)$ & $9.5 \pm 1.0(8)$ & $0.47 \pm 0.07$ \\
\hline $\mathrm{K}^{+}, 50 \mathrm{mM}$ & $-24.9 \pm 2.5(22)$ & $-55.1 \pm 2.8(22)$ & $30.2 \pm 2.0(22)$ & $16.7 \pm 3.2(8)$ & $0.33 \pm 0.07(8$ \\
\hline Difference & $-18.4 \pm 2.6$ & $27.3 \pm 2.7$ & $-46.0 \pm 2.0$ & $7.1 \pm 2.6$ & $-0.14 \pm 0.04$ \\
\hline$P$ & $<0.001$ & $<0.001$ & $<0.001$ & $<0.05$ & $<0.05$ \\
\hline \multicolumn{6}{|l|}{ UNX } \\
\hline $\mathrm{K}^{+}, 5 \mathrm{mM}$ & $-25.0 \pm 1.5(18)$ & $-103.7 \pm 2.2(18)$ & $78.5 \pm 2.1(18)$ & $11.4 \pm 1.0(9)$ & $0.38 \pm 0.05$ \\
\hline $\mathrm{K}^{+}, 50 \mathrm{mM}$ & $-53.5 \pm 2.1(18)$ & $-76.0 \pm 3.2(18)$ & $22.6 \pm 3.2(18)$ & $32.1 \pm 5.2(9)$ & $0.17 \pm 0.06$ \\
\hline Difference & $-28.5 \pm 1.9^{*}$ & $27.7 \pm 2.3$ & $-55.9 \pm 2.8^{*}$ & $20.7 \pm 4.5^{* *}$ & $-0.21 \pm 0.02$ \\
\hline$P$ & $<0.001$ & $<0.001$ & $<0.001$ & $<0.005$ & $<0.001$ \\
\hline
\end{tabular}

Values are mean \pm SE. Numerals in parentheses indicate number of experiments. ${ }^{*} P<0.01$ vs. control; ${ }^{* *} P<0.05$. Data were obtained from the same experiments.

was significantly decreased and the $f R_{\mathrm{A}}$ was significantly increased. Although the pattern of the responses of $G_{\mathrm{T}}$ and $f R_{\mathrm{A}}$ in the UNX group was the same as that in the control group, the changes in $G_{\mathrm{T}}$ were much greater in the UNX group. These
CONTROL
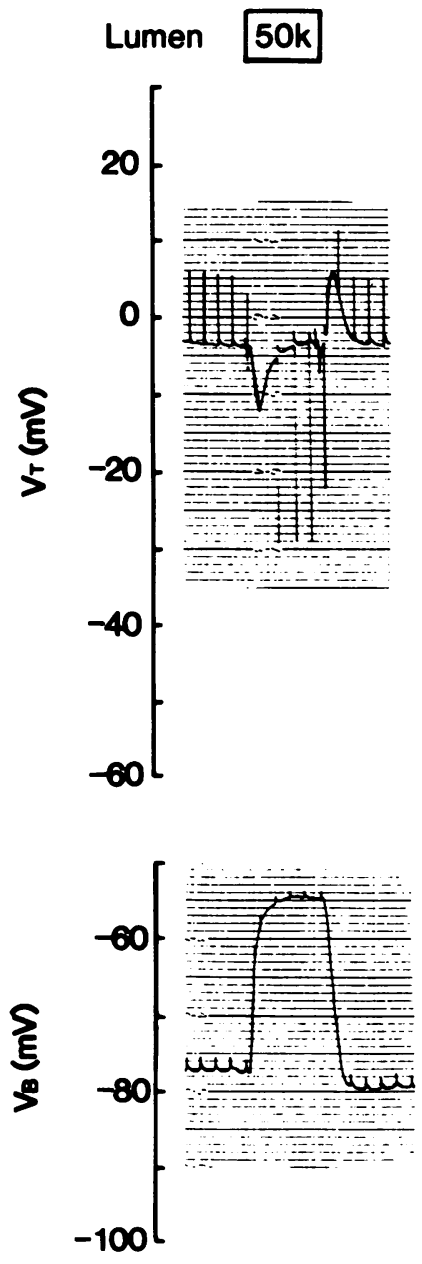

UNX
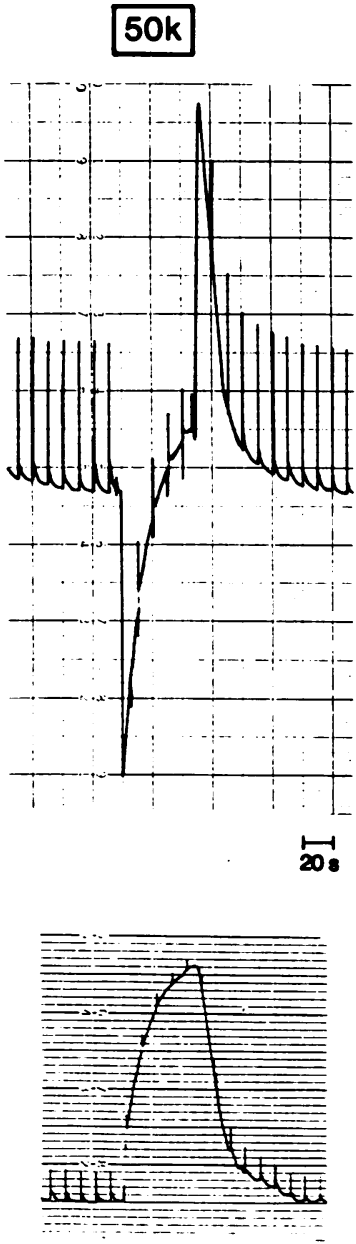

Figure 3. Typical tracings of $V_{\mathrm{T}}$ and $V_{\mathrm{B}}$ upon raising the perfusate $\mathrm{K}^{+}$ concentration from 5 to $50 \mathrm{mM}$ in the tubules of CONTROL and UNX groups. results indicate that $\mathrm{Ba}^{2+}$-sensitive $\mathrm{K}^{+}$conductance in the apical membrane of the CD cell in the tubules from UNX rabbits is also stimulated.

Effects of UNX on electrical properties of the basolateral membrane. As summarized in Table III, the tubules from UNX rabbits had a 1.6-fold increase in $G_{\mathrm{B}}$. We next examined whether this increase in $G_{\mathrm{B}}$ is due to either an increase in $\mathrm{K}^{+}$ conductance and/or an increase in $\mathrm{Cl}^{-}$conductance in the basolateral membrane. Therefore, we assessed the relative conductive properties of the basolateral membrane of both groups using rapid bath exchange rates. Typical tracings of $V_{B}$ in the tubules of both groups upon changing bath $\mathrm{Cl}^{-}$and $\mathrm{K}^{+}$concentrations are illustrated in Fig. 5. When bath $\mathrm{Cl}^{-}$concentration was decreased from 120.6 to $12 \mathrm{mM}$, the $V_{\mathrm{B}}$ in the tubules from both groups was rapidly depolarized within several seconds and was then repolarized to a new steady state level. Although the pattern of the response was the same in both groups, the magnitude of the initial peak depolarization of the $V_{\mathbf{B}}$ was significantly lower in the UNX group $(23.3 \pm 2.8 \mathrm{mV}, n=15, P$ $<0.05)$ than in the control group $(28.3 \pm 1.6 \mathrm{mV}, n=16)$. At that time, the change in electromotive force $(\Delta \mathrm{EMF})$ was also significantly lower in the UNX group $(25.8 \pm 2.1$ vs. $35.7 \pm 2.2$ $\mathrm{mV}, P<0.01)$. When bath $\mathrm{K}^{+}$concentration was increased from 5 to $50 \mathrm{mM}$, the $V_{\mathrm{B}}$ in the tubules of the control group was rapidly depolarized within several seconds and was then slowly depolarized further over the next $30 \mathrm{~s}$. Similar pattern of the response of $V_{B}$ was also observed in the tubules of the UNX group. However, the initial peak changes in $V_{\mathrm{B}}$ were significantly greater in the UNX group $(35.1 \pm 1.9 \mathrm{mV}, n=25, P$ $<0.001)$ when compared with the control group (17.8 \pm 1.3 $\mathrm{mV}, n=22)$. The $\Delta \mathrm{EMF}$ upon raising bath $\mathrm{K}^{+}$was also significantly greater in the UNX group $(30.9 \pm 1.5$ vs. $10.4 \pm 0.9 \mathrm{mV}, P$ $<0.001)$. These findings indicate that the basolateral membrane of the CD cell in the CCDs from the UNX rabbits is more selective to $\mathrm{K}^{+}$.

Table VII shows the effects of raising the bath $\mathrm{K}^{+}$concentration on barrier voltages and conductances at the initial peak response. When the bath $\mathrm{K}^{+}$concentration was increased in the tubules of both groups, the $G_{\mathrm{T}}$ and the $f R_{\mathrm{A}}$ were significantly increased. However, the changes in $G_{\mathrm{T}}$ and the $f R_{\mathrm{A}}$ were amplified in the UNX group. Taken together, these results indicate that the basolateral membrane $\mathrm{K}^{+}$conductance is stimulated upon UNX. 


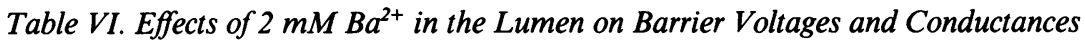

\begin{tabular}{|c|c|c|c|c|c|}
\hline & $V_{\mathrm{T}}$ & $V_{\mathbf{B}}$ & $V_{\mathrm{A}}$ & $G_{\mathrm{T}}$ & $f R_{\mathrm{A}}$ \\
\hline & $m V$ & $m V$ & $m V$ & $\mathrm{mS} \cdot \mathrm{cm}^{-2}$ & \\
\hline \multicolumn{6}{|l|}{ Control } \\
\hline Without $\mathrm{Ba}^{2+}$ & $-9.3 \pm 2.0(12)$ & $-83.4 \pm 2.1(12)$ & $74.1 \pm 2.4(12)$ & $8.7 \pm 0.6(12)$ & $0.38 \pm 0.03(12)$ \\
\hline With $\mathrm{Ba}^{2+}$ & $-16.7 \pm 2.2(12)$ & $-62.3 \pm 1.7(12)$ & $45.6 \pm 3.0(12)$ & $5.3 \pm 0.4(12)$ & $0.83 \pm 0.02(12)$ \\
\hline Difference & $-7.2 \pm 0.8$ & $21.1 \pm 2.0$ & $-28.4 \pm 2.4$ & $-3.4 \pm 0.4$ & $0.45 \pm 0.02$ \\
\hline$P$ & $<0.001$ & $<0.001$ & $<0.001$ & $<0.001$ & $<0.001$ \\
\hline \multicolumn{6}{|l|}{ UNX } \\
\hline Without $\mathrm{Ba}^{2+}$ & $-24.9 \pm 1.2(17)$ & $-97.2 \pm 1.9(17)$ & $72.2 \pm 1.4(17)$ & $10.9 \pm 0.8(17)$ & $0.34 \pm 0.04(17)$ \\
\hline With $\mathrm{Ba}^{2+}$ & $-40.4 \pm 1.8(17)$ & $-77.2 \pm 2.8(17)$ & $36.8 \pm 2.4(17)$ & $5.0 \pm 0.3(17)$ & $0.80 \pm 0.01(17)$ \\
\hline Difference & $-15.4 \pm 0.9^{*}$ & $20.0 \pm 1.4$ & $-35.4 \pm 1.5^{* *}$ & $-5.8 \pm 0.7^{* *}$ & $0.46 \pm 0.04$ \\
\hline$P$ & $<0.001$ & $<0.001$ & $<0.001$ & $<0.001$ & $<0.001$ \\
\hline
\end{tabular}

Values are mean \pm SE. Numerals in parentheses include number of experiments. ${ }^{*} P<0.001$ vs. control; ${ }^{* *} P<0.05$. Data were obtained from the same experiments.

To further characterize the basolateral membrane $\mathrm{K}^{+}$conductive property in the UNX group, we added $2 \mathrm{mM} \mathrm{Ba}{ }^{2+}$ to the bath. A typical tracing of $V_{\mathrm{T}}$ and $V_{\mathrm{B}}$ in the UNX group is illustrated in Fig. 6. The effects of the addition of $\mathrm{Ba}^{2+}$ to the bath on the electrical properties at the initial peak response are summarized in Table VIII. In the control group, addition of $\mathrm{Ba}^{2+}$ to the bath had no significant effects on $V_{\mathrm{T}}$ and $V_{\mathrm{B}}$, al-

CONTROL

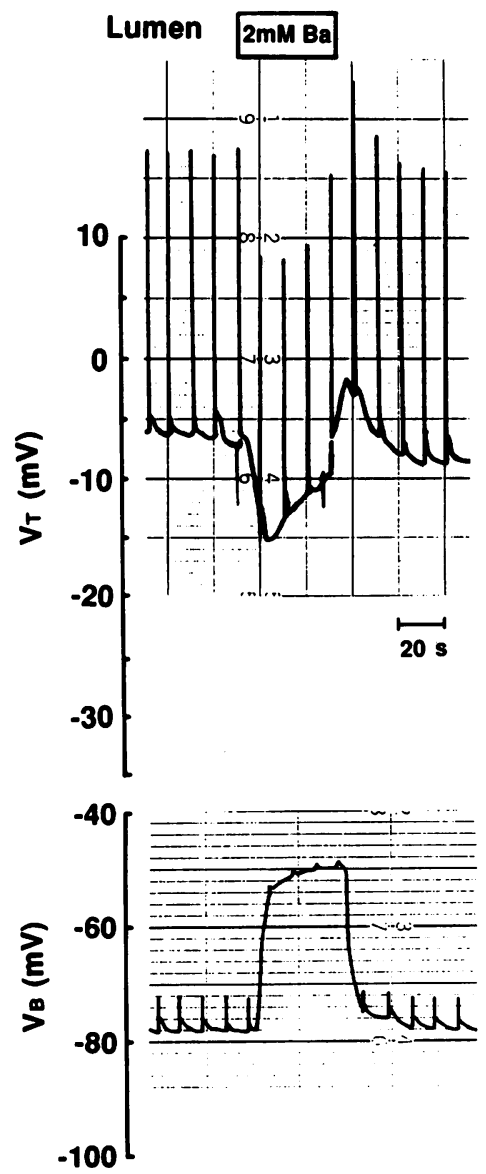

\section{UNX}

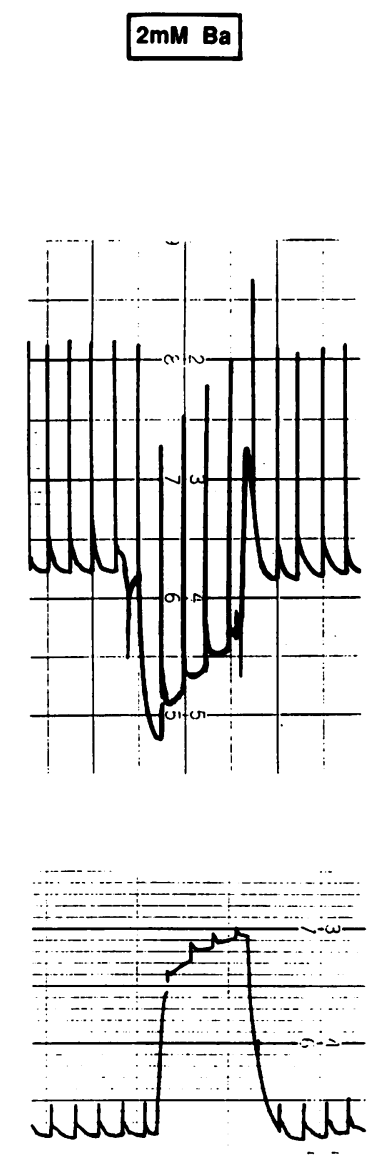

Figure 4. Typical tracings of $V_{\mathrm{T}}$ and $V_{\mathrm{B}}$ upon addition of $2 \mathrm{mM} \mathrm{Ba} \mathrm{Ba}^{2+}$ to the perfusate in the tubules of CONTROL and UNX groups. though it caused both $G_{\mathrm{T}}$ and $f R_{\mathrm{A}}$ to decrease significantly ( Table VIII). These findings indicate that $\mathrm{K}^{+}$is close to equilibrium across the basolateral membrane. These results are in good agreement with those reported by Sansom and O'Neil (24), in CCDs from normal rabbits. In sharp contrast to the control group, when $2 \mathrm{mM} \mathrm{Ba}^{2+}$ was added to the UNX group, $V_{\mathrm{T}}$ and $V_{\mathrm{B}}$ were rapidly hyperpolarized within several seconds by $\sim 4 \mathrm{mV}$ in parallel with decreases in $G_{\mathrm{T}}$ and $f R_{\mathrm{A}}$. These results are consistent with $\mathrm{Ba}^{2+}$ blockade of a $\mathrm{K}^{+}$current directed into the cell from the bath in the UNX group. These findings are also observed in the CCDs from desoxycorticosterone acetate-treated rabbits (24).

As shown in Fig. 1, the $-V_{\mathrm{B}}$ was increased by $\sim 20 \mathrm{mV}$ in the tubules from UNX rabbits, suggesting that UNX stimulates the $\mathrm{Na}^{+} / \mathrm{K}^{+}$ATPase pump activity in the basolateral membrane of the CD cell. To further confirm this proposal, we added $10^{-4} \mathrm{M}$ ouabain to the bath, and observed the electrical properties. Typical tracings of $V_{\mathrm{B}}$ in the tubules of both groups are illustrated in Fig. 7. In the control group addition of ouabain to the bath resulted in a two-phase depolarization of the basolateral membrane, with an initial rapid depolarization followed by a slow and more prolonged phase. These findings are similar to those reported by Koeppen et al. (9) and Sansom and O'Neil (24) in rabbit CCD, and by Helman et al. (25) in frog skin. This initial fast-depolarizing phase has been attributed to direct inhibition of an electrogenic $\mathrm{Na}^{+}-\mathrm{K}^{+}$pump, since during this fast-depolarizing phase there was no signifcant effects on $G_{\mathrm{T}}$ or $f R_{\mathrm{A}}$ (Table IX). Similar pattern of responses of $V_{\mathrm{B}}$ upon addition of bath ouabain was also observed in the UNX group. However, the initial peak changes in $V_{B}$ were significantly higher in the UNX group, as shown in Table IX. These results are consistent with the view that the $\mathrm{Na}^{+} / \mathrm{K}^{+}$ ATPase pump activity in the tubules from UNX rabbits is also stimulated. This is also supported by the evidence that the $\mathrm{Na}^{+} / \mathrm{K}^{+}$ATPase activity of the CCDs from the remnant kidneys of the rabbits $14 \mathrm{~d}$ after the surgery was stimulated (6).

\section{Effects of UNX on plasma aldosterone concentration}

The results described above are quite similar to those seen in the CCDs from chronic DOCA-treated rabbits $(9,23,24,26)$. To examine whether the electrical properties in the apical as well as the basolateral membranes of the CD cell in the CCDs from UNX rabbits are the result of an increased plasma aldoste- 
Table VII. Effects of Bath $\mathrm{K}^{+}$Elevation from 5 to $50 \mathrm{mM}$ on Barrier Voltages and Conductances

\begin{tabular}{lcccc}
\hline & $V_{\mathrm{T}}$ & $V_{\mathrm{B}}$ & $G_{\mathrm{T}}$ & $f R_{\mathrm{A}}$ \\
\hline & $m V$ & $m V$ & $m s \cdot \mathrm{cm}^{-2}$ & \\
Control & & & & \\
$\mathrm{K}^{+}, 5 \mathrm{mM}$ & $-5.5 \pm 1.4(22)$ & $-80.8 \pm 1.8(22)$ & $10.6 \pm 0.7(9)$ & $0.33 \pm 0.07(9)$ \\
$\mathrm{K}^{+}, 50 \mathrm{mM}$ & $9.6 \pm 1.5(22)$ & $-63.0 \pm 1.8(22)$ & $1.6 \pm 0.6$ & $0.43 \pm 0.08(9)$ \\
Difference & $16.2 \pm 1.1$ & $17.8 \pm 1.3$ & $<0.05$ & $0.10 \pm 0.01$ \\
$P$ & $<0.001$ & $<0.001$ & $11.3 \pm 1.3(10)$ & $<0.001$ \\
$\mathrm{UNX}$ & & & $17.9 \pm 2.3(10)$ & $0.21 \pm 0.04(10)$ \\
$\mathrm{K}^{+}, 5 \mathrm{mM}$ & $-21.3 \pm 1.2(25)$ & $-98.4 \pm 2.1(25)$ & $6.6 \pm 1.1^{* *}$ & $0.40 \pm 0.05(10)$ \\
$\mathrm{K}^{+}, 50 \mathrm{mM}$ & $11.5 \pm 1.1(25)$ & $-63.2 \pm 2.4(25)$ & $<0.001$ & $0.18 \pm 0.03^{* *}$ \\
Difference & $32.7 \pm 1.3^{*}$ & $35.1 \pm 1.9^{*}$ & $<0.001$ \\
$P$ & $<0.001$ & $<0.001$ & & $<$ \\
\hline
\end{tabular}

Values are mean \pm SE. Numerals in parentheses indicate number of experiments. ${ }^{*} P<0.001$ vs. control; ${ }^{* *} P<0.05$. Data were obtained from the same experiments.

rone concentration, we measured plasma aldosterone levels at $16 \mathrm{~h}$ and 7 and $14 \mathrm{~d}$ after surgery in the two groups. Plasma aldosterone levels at $16 \mathrm{~h}$ and 7 and $14 \mathrm{~d}$ in the UNX rabbits were $66.0 \pm 8.1(n=6), 71.0 \pm 8.9(n=5)$, and $60.7 \pm 7.8 \mathrm{pg} / \mathrm{ml}$ $(n=9)$, respectively. These values were not significantly different from those in the control rabbits at any of the time points ( 16 h: $73.7 \pm 6.5, n=7 ; 7$ d: $72.6 \pm 5.3, n=5 ; 14$ d: $64.9 \pm 7.0$ $\mathrm{pg} / \mathrm{ml}, n=10)$. Thus, UNX had no effects on plasma aldosterone concentration.

\section{CONTROL}
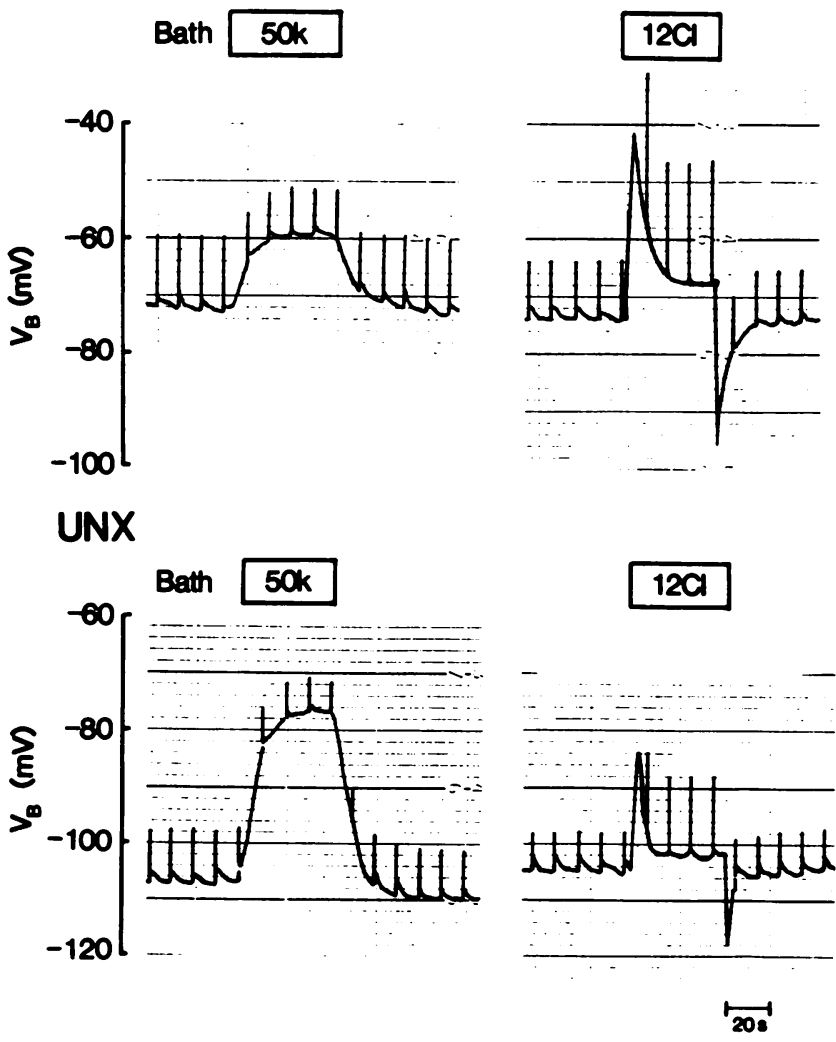

Figure 5. Typical tracings of $V_{\mathrm{B}}$ upon raising bath $\mathrm{K}^{+}$concentration and lowering bath $\mathrm{Cl}^{-}$concentration in the tubules of CONTROL and UNX groups.

\section{Discussion}

The present study was designed to determine the cellular mechanisms whereby a reduction of renal mass leads to an increased capacity to reabsorb $\mathrm{Na}^{+}$and secrete $\mathrm{K}^{+}$in the CCD. We found that UNX stimulated both electrogenic $\mathrm{Na}^{+}-\mathrm{K}^{+}$pump activity and $\mathrm{K}^{+}$conductance in the basolateral membrane and $\mathrm{Na}^{+}$and $\mathrm{K}^{+}$conductances in the apical membrane. The CCD from remnant kidneys also exhibited structural hypertrophy. These functional and morphological adaptations occurred independently of changes in plasma aldosterone. This study was the first to demonstrate the electrophysiological properties of the apical and the basolateral membranes of the CD cell from UNX rabbits.

Effects of UNX on electrical properties of the apical membrane. A reduction of renal mass is known to stimulate both $\mathrm{Na}^{+}$reabsorption (4) and $\mathrm{K}^{+}$secretion (5) in the CCDs from the remnant kidney of the rabbit after nephrectomy. However, whether the changes in membrane conductances contribute to the functional adaptation in the CCD after nephrectomy has not yet been evaluated. In the present study, we demonstrated that UNX led to an increase in $G_{\mathrm{A}}$.

$\mathrm{Na}^{+}$absorption in the rabbit CCD is initiated by passive $\mathrm{Na}^{+}$diffusion from the lumen into the cell down its electrochemical gradient via a $\mathrm{Na}^{+}$channel and is then actively extruded from the cell into the peritubular space via the $\mathrm{Na}^{+}-\mathrm{K}^{+}$ exchange pump located in the basolateral membrane (9-11, $15,16,21)$. In the present study, we observed that amiloridesensitive changes in $V_{\mathrm{A}}, f R_{\mathrm{A}}$, and $G_{\mathrm{T}}$ were much greater in the UNX group. These observations indicate that amiloride-sensitive $\mathrm{Na}^{+}$conductance in the apical membrane is stimulated upon UNX, resulting in an increase in $\mathrm{Na}^{+} / \mathrm{K}^{+}$ATPase activity. Such effects of UNX on the $\mathrm{Na}^{+}$conductance are consistent with the reported increase in $\mathrm{Na}^{+}$reabsorption in the CCD from the remnant kidneys of the rabbit after nephrectomy.

$\mathrm{K}^{+}$is secreted in the rabbit CCD by a two-step process that involves uptake from the blood into the cell via the basolateral membrane $\mathrm{Na}^{+}-\mathrm{K}^{+}$pump and passive diffusion down the cell to the lumen through a large apical membrane conductive pathway $(9-11,15,16,21,26)$. In the present study, we also demonstrated that the changes in $V_{\mathrm{A}}$ upon raising the perfusate $\mathrm{K}^{+}$concentration were exaggerated in the CCDs from UNX rabbits. Furthermore, the changes in $V_{\mathrm{A}}$ upon addition of lu- 
Table VIII. Effects of $2 \mathrm{mM} \mathrm{Ba} a^{2+}$ in the Bath on Barrier Voltages and Conductances

\begin{tabular}{lcccc}
\hline & $V_{\mathrm{T}}$ & $V_{\mathrm{B}}$ & $G_{\mathrm{T}}$ & $f R_{\mathrm{A}}$ \\
\hline & $m V$ & $m V$ & $m S \cdot \mathrm{cm}^{-2}$ & \\
Control & & & & \\
Without $\mathrm{Ba}^{2+}$ & $-6.0 \pm 1.6(25)$ & $-80.0 \pm 1.4(25)$ & $10.3 \pm 1.1(7)$ & $0.50 \pm 0.07(7)$ \\
With Ba & $-5.0 \pm 1.9(25)$ & $-78.4 \pm 1.9(25)$ & $9.5 \pm 1.0(7)$ & $0.46 \pm 0.07(7)$ \\
Difference & $1.0 \pm 0.6$ & $1.6 \pm 0.9$ & $-0.8 \pm 0.3$ & $-0.04 \pm 0.007$ \\
$P$ & $\mathrm{NS}$ & $\mathrm{NS}$ & $<0.005$ & $<0.01$ \\
UNX & & & $11.2 \pm 0.8(10)$ & $0.33 \pm 0.03(10)$ \\
Without $\mathrm{Ba}^{2+}$ & $-19.7 \pm 1.5(16)$ & $-101.5 \pm 2.9(16)$ & $8.8 \pm 0.6(10)$ & $0.19 \pm 0.03(10)$ \\
With Ba & $-23.7 \pm 1.9(16)$ & $-106.0 \pm 3.1(16)$ & $-2.4 \pm 0.5^{* *}$ & $-0.14 \pm 0.03^{* *}$ \\
Difference & $-4.3 \pm 0.7^{*}$ & $-4.5 \pm 0.6^{*}$ & $<0.005$ & $<0.001$ \\
$P$ & $<0.001$ & $<0.001$ & & \\
\hline
\end{tabular}

Values are mean \pm SE. Numerals in parentheses indicate number of experiments. ${ }^{*} P<0.001$ vs. control; ${ }^{* *} P<0.05$. Data were obtained from the same experiments.

minal $\mathrm{Ba}^{2+}$ were also much greater in the UNX group. These findings are consistent with the view that the $\mathrm{Ba}^{2+}$-sensitive $\mathrm{K}^{+}$ conductance in the apical membrane of the $\mathrm{CD}$ cell is also stimulated after UNX. Therefore, the increase in net $\mathrm{K}^{+}$secre-
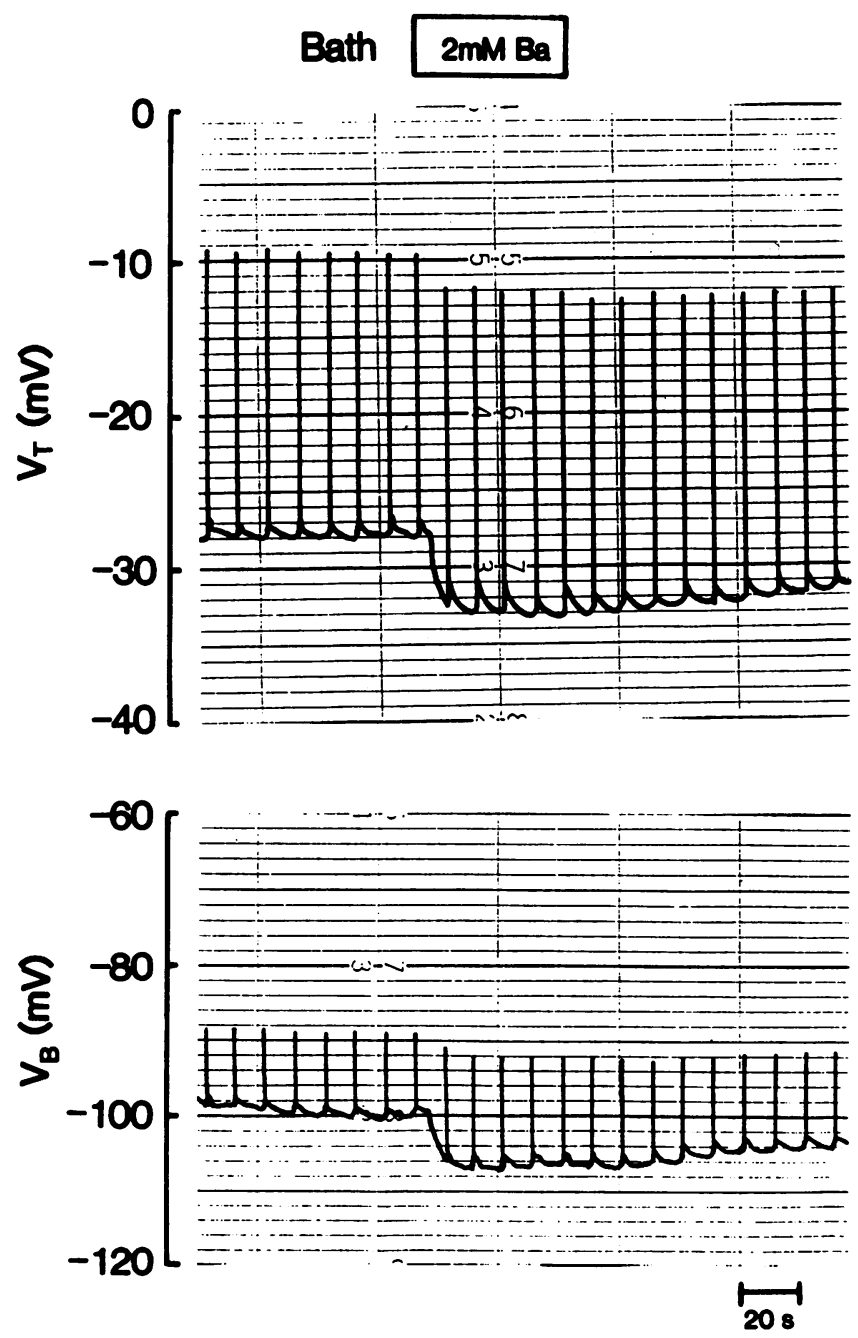

Figure 6. Typical tracings of $V_{\mathrm{T}}$ and $V_{\mathrm{B}}$ upon addition of $2 \mathrm{mM} \mathrm{Ba}^{2+}$ to the bath in a tubule from the UNX group. tion in the CCD from UNX rabbits can be, at least in part, explained by an increase in the apical membrane $\mathrm{K}^{+}$conductance.

Effects of UNX on electrical properties of the basolateral membrane. As shown in Table III, the $G_{\mathrm{B}}$ of the CD cell also appears to be under the influence of UNX. The $G_{\mathrm{B}}$ was observed to increase by a 1.6-fold after UNX. The basolateral membrane conductive pathways of the CD cell in the CCDs from normal rabbits are a dominant $\mathrm{Cl}^{-}$conductive pathway and a small $\mathrm{K}^{+}$conductive pathway $(14,16,24,27)$. Using changes in basolateral membrane electromotive force upon abrupt changes in bath $\mathrm{K}^{+}$and $\mathrm{Cl}^{-}$concentrations, we can estimate the relative conductance of $\mathrm{K}^{+}$and $\mathrm{Cl}^{-}$in the basolateral membrane. Thus, the basolateral membrane of the CD cell in the UNX group is predominantly $\mathrm{K}^{+}$selective. These observations strikingly resemble those seen in the basolateral membrane of the CD cell in the CCD from chronic mineralocorticoid-treated rabbits $(24,26)$.

In the CCDs from control rabbits, $V_{\mathrm{B}}$ was observed to be near the Nernst equilibrium potential for $\mathrm{K}^{+}$across the basolateral membrane of the $C D$ cell $\left(E_{B}^{K}\right)$, since addition of $\mathrm{Ba}^{2+}, a$ blocker of $\mathrm{K}^{+}$channel, to the bath had no effect on $V_{\mathrm{B}}$. In contrast, after UNX, $-V_{B}$ was elevated by $\sim 20 \mathrm{mV}$ so that a driving force for $\mathrm{K}^{+}$entry into the cell would exist. Under these conditions $\mathrm{Ba}^{2+}$ added to the bath could block this inwardly directly passive $\mathrm{K}^{+}$flux and the basolateral membrane should hyperpolarize, as was observed. Similar findings were also reported in the CD cell from chronic DOCA-treated rabbits (24). It can be thus concluded from these considerations that, in the CCDs from UNX rabbits, the basolateral membrane of the CD cell is indeed hyperpolarized above $\mathrm{E}_{\mathrm{B}}^{\mathbf{K}}$, providing a driving force for passive $\mathrm{K}^{+}$uptake across the basolateral membrane. Therefore, increases in both $\mathrm{K}^{+}$conductance and the driving force for $\mathrm{K}^{+}$across the basolateral membrane could result in an increased $\mathrm{K}^{+}$uptake across the basolateral membrane in the CCDs from UNX rabbits.

In the tubules of UNX rabbits of the present study, the basolateral membrane of the CD cell hyperpolarized by $\sim 20$ $\mathrm{mV}$ above the values of the tubules of control rabbits. In addition, the initial peak changes in $V_{B}$ upon addition of ouabain to the bath were significantly greater in the UNX group, as shown in Fig. 7 and Table IX. From these two observations it is indi- 
Table IX. Effects of $10^{-4} \mathrm{M}$ Ouabain in the Bath on Barrier Voltages and Conductances

\begin{tabular}{lcccc}
\hline & $V_{\mathrm{T}}$ & $V_{\mathbf{B}}$ & $G_{\mathrm{T}}$ & $f R_{\mathrm{A}}$ \\
\hline & $m V$ & $m V$ & $m s \cdot \mathrm{cm}^{-2}$ & \\
Control & & & & \\
Without ouabain & $-12.1 \pm 4.4(9)$ & $-84.4 \pm 3.7(9)$ & $8.6 \pm 0.5(6)$ & $0.44 \pm 0.03(6)$ \\
With ouabain & $-3.5 \pm 3.6(9)$ & $-74.3 \pm 3.9(9)$ & $8.3 \pm 0.6(6)$ & $0.45 \pm 0.03(6)$ \\
Difference & $8.5 \pm 1.5$ & $10.1 \pm 0.9$ & $-0.3 \pm 0.2$ & $0.003 \pm 0.006$ \\
$P$ & $<0.001$ & $<0.001$ & $\mathrm{NS}$ & $\mathrm{NS}$ \\
UNX & & & $10.0 \pm 0.6(5)$ & $0.36 \pm 0.03(5)$ \\
Without ouabain & $-19.7 \pm 2.2(12)$ & $-101.0 \pm 3.6(12)$ & $9.5 \pm 0.7(5)$ & $0.37 \pm 0.02(5)$ \\
With ouabain & $-4.8 \pm 1.1(12)$ & $-79.2 \pm 3.3(12)$ & $-0.5 \pm 0.4$ & $0.016 \pm 0.007$ \\
Difference & $14.8 \pm 1.5^{*}$ & $22.4 \pm 2.0^{*}$ & $\mathrm{NS}$ & $\mathrm{NS}$ \\
$P$ & $<0.001$ & $<0.001$ & & \\
\hline
\end{tabular}

Values are mean \pm SE. Numerals in parentheses indicate number of experiments. ${ }^{*} P<0.001$ vs. control. Data indicate the initial fast response of each parameter upon addition of ouabain. Data were obtained from the same experiments.

cated that the electrogenic $\mathrm{Na}^{+}-\mathrm{K}^{+}$pump activity in the basolateral membrane of the CD cell is stimulated upon UNX, although the maximum pump current was not estimated in the present study. This increase in basolateral pump activity is consistent with biochemical evidence that basolateral $\mathrm{Na}^{+} / \mathrm{K}^{+}$ ATPase activity is amplified in the UNX rats (7) and rabbits

\section{CONTROL}

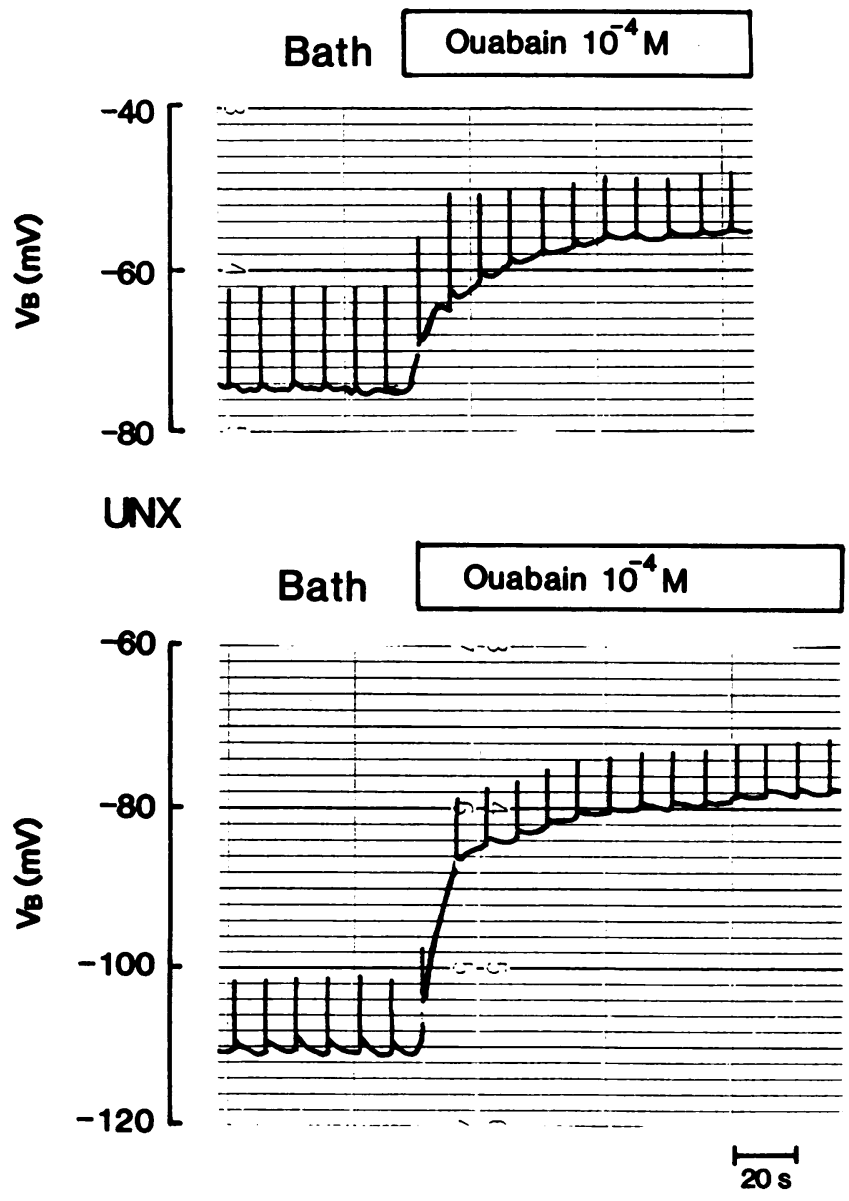

Figure 7. Typical tracings of $V_{\mathrm{B}}$ upon addition of $10^{-4} \mathrm{M}$ ouabain to the bath in the tubules of CONTROL and UNX groups.
(6), and that there is also an amplification of the basolateral membrane area of the $\mathrm{CD}$ cell in the initial collecting duct from 75\%-nephrectomized rats $(8)$.

Effects of UNX on electrical properties of the tight junction. In the present study, we demonstrated that UNX caused $G_{\mathrm{Tj}}$ to decrease by $32 \%$. Sansom et al. (27), using microelectrode and cable analysis, reported that the paracellular pathway in the rabbit $\mathrm{CCD}$ is $\mathrm{Cl}^{-}$permselective. We speculate thus that $\mathrm{UNX}$ would induce a decrease in the conductance of the paracellular $\mathrm{Cl}^{-}$-conductive pathway. A decrease in $G_{\mathrm{T} j}$ upon UNX may be at least in part responsible for the further increase in the magnitude of the lumen-negative $V_{\mathrm{T}}$. This would therefore increase the net transepithelial driving force for $\mathrm{K}^{+}$secretion.

Mechanisms responsible for the adaptations in the CCD from the remnant kidney after $U N X$. The mechanisms for the observed adaptations of the apical as well as the basolateral membranes of the CD cell after UNX are not fully understood at the present time. Several factors, including mineralocorticoids $(7,28), \mathrm{Na}^{+}$delivery to the $\mathrm{CCD}(29-32)$, and $\mathrm{K}^{+}$balance of the animal $(5,33)$, could be responsible for the increased transport capacity for $\mathrm{Na}^{+}$and $\mathrm{K}^{+}$in the CCDs from the remnant kidneys.

Mineralocorticoid hormones such as aldosterone are known to increase $\mathrm{Na}^{+}$reabsorption and $\mathrm{K}^{+}$secretion in the rabbit $\mathrm{CCD}(11,16,20,21)$. These effects are accompanied by increasing the activity of $\mathrm{Na}^{+} / \mathrm{K}^{+}$ATPase $(18,19)$ and the basolateral membrane area of the CD cell (17). This adaptive stimulation in $\mathrm{Na}^{+}$reabsorption and $\mathrm{K}^{+}$secretion is also attributed to increases in apical membrane $\mathrm{Na}^{+}$and $\mathrm{K}^{+}$conductances $(9,16,23)$ and to an increase in basolateral membrane $\mathrm{K}^{+}$conductance (24). Similar changes in membrane conductances of the CD cell after UNX were also observed in the present study. Aldosterone would thus play an important role in regulating the observed adaptation (28). However, our results do not support this hypothesis for several reasons. First, plasma aldosterone levels did not change during the time course of the nephrectomy in this study. Similar results are reported by Fine et al. ( 5 ) in 75\%-nephrectomized rabbits 3-4 wk after the surgery. Scherzer et al. (6) also arrived at the same conclusion in UNX rabbits $14 \mathrm{~d}$ after the surgery. In contrast to our study, Vehaskari and Herndon (28) reported that plasma aldosterone levels were significantly elevated at $16 \mathrm{~h}$ and $7 \mathrm{~d}$ in 
75\%-nephrectomized rabbits. The reasons for the differences between the two studies are not clear at the present time; the renal function of our remnant kidney animals was, however, within the normal range. On the other hand, the renal function of their animals was moderately impaired (serum creatinine levels: $\sim 1.5-2.5 \mathrm{mg} / \mathrm{dl}$ ) due to more extensive reduction of renal mass. According to Hené et al. (34), plasma aldosterone levels are elevated when creatinine clearance is lower than $50 \%$ of normal subjects. Accordingly, elevated plasma aldosterone levels in their animals may possibly be due to impaired renal function. Second, a significant and sustained increase in plasma aldosterone levels has not been a consistent finding in situations in which renal mass is reduced to a similar extent as in our experiments. Therefore, we conclude that the observed functional and morphological adaptations in the CCDs from remnant kidneys after UNX are independent of plasma aldosterone.

We also propose that a reduction in renal mass effects to enhance cellular uptake of $\mathrm{Na}^{+}$in the apical membrane, and then to stimulate $\mathrm{Na}^{+}$absorption. This, in turn, increases the amount of $\mathrm{Na}^{+} / \mathrm{K}^{+}$ATPase pump, which is manifested as an increase in the surface area of the basolateral membrane of the CD cell. Several lines of evidence also support this proposal. First, free-flow micropuncture experiments of Diezi et al. (2) showed that UNX increased single-nephron GFR and sodium delivery to the superficial distal tubule, augmenting sodium absorption by this segment. Second, when the delivery of sodium to the distal tubule, including the CCD, is chronically increased by diuretics such as amiloride and furosemide there is an increase in the $\mathrm{Na}^{+} / \mathrm{K}^{+}$ATPase activity in this segment, independent of mineralocorticoid $(29,30)$. Furthermore, Stanton and Kaissling (32) have also shown that a chronic increase in $\mathrm{Na}^{+}$delivery to and $\mathrm{Na}^{+}$uptake by the distal tubule of the rat in vivo by furosemide administration stimulated $\mathrm{Na}^{+}$ absorption, independently of a change in aldosterone levels. The amplification of the basolateral membrane area of the CD cell is also associated with an increase in $\mathrm{Na}^{+}$delivery to and in cell $\mathrm{Na}^{+}$uptake by the CCD (31).

Another factor that would alter the conductances of the apical and the basolateral membranes of the CD cell is dietary $\mathrm{K}^{+}$intake. A high $\mathrm{K}^{+}$intake has been reported to stimulate $\mathrm{Na}^{+} / \mathrm{K}^{+}$ATPase activity in the CCD (35) and to induce the amplification of the basolateral membrane of the CD cell (36), independent of aldosterone. In addition, a high $\mathrm{K}^{+}$diet stimulates net $\mathrm{Na}^{+}$reabsorption and $\mathrm{K}^{+}$secretion in the $\mathrm{CCD}$ from adrenalectomized rabbits (37). These changes are also associated with increases in apical $\mathrm{Na}^{+}$and $\mathrm{K}^{+}$conductances and in basolateral electrogenic $\mathrm{Na}^{+}-\mathrm{K}^{+}$pump activity (15). It seems, however, unlikely that changes in $\mathrm{K}^{+}$balance or transport would induce the observed adaptation in the CD cell, since plasma $\mathrm{K}^{+}$levels were not significantly elevated in the UNX rabbits (Table II). Finally, it is possible that other hormones, such as thyroid hormone and growth hormone, and growth factors may be involved in the mechanisms of the adaptations after nephrectomy.

In summary, we conclude that $(a)$ UNX increases both apical membrane $\mathrm{Na}^{+}$and $\mathrm{K}^{+}$conductances and basolateral membrane $\mathrm{K}^{+}$conductance; $(b)$ the basolateral membrane in the tubules of UNX rabbits is more selective to $\mathrm{K}^{+} ;(c)$ UNX increases basolateral membrane electrogenic $\mathrm{Na}^{+}-\mathrm{K}^{+}$pump activity. This results in a hyperpolarization of the basolateral membrane, which may increase passive $\mathrm{K}^{+}$entry into the cell across the basolateral membrane; and $(d)$ These changes occur independently of plasma aldosterone.

\section{Acknowledgments}

We would like to thank Ms. H. Kasakura for expert secretarial assistance in preparing the manuscript.

This work was supported in part by grants from the Japanese Kidney Foundation (Jinkenkyukai) and the Ministry of Education, Science, and Culture of Japan (No. 01570366).

\section{References}

1. Meyer, T. W., J. W. Scholey, and B. M. Brenner. 1991. Nephron adaptation to renal injury. In The Kidney. 4th ed. B. M. Brenner, and F. C. Rector, editors Saunders, Philadelphia. 1871-1908.

2. Diezi, J., P. Michoud, A. Grandchamp, and G. Giebisch. 1976. Effects of nephrectomy on renal salt and water transport in the remaining kidney. Kidney Int. 10:450-462.

3. Hayslett, J. P. 1979. Functional adaptation to reduction in renal mass. Physiol. Rev. 59:137-164.

4. Vehaskari, V. M., K. S. Hering-Smith, S. Klahr, and L. L. Hamm. 1989. Increased sodium transport by cortical collecting tubules from remnant kidneys. Kidney Int. 36:89-95.

5. Fine, L. G., N. Yanagawa, R. G. Schultze, M. Tuck, and W. Trizna. 1979. Functional profile of the isolated uremic nephron. Potassium adaptation in the rabbit cortical collecting tubule. J. Clin. Invest. 64:1033-1043.

6. Scherzer, P., H. Wald, and J. W. Czaczkes. 1985. Na-K-ATPase in isolated rabbit tubules after unilateral nephrectomy and $\mathrm{Na}^{+}$loading. Am. J. Physiol. 248:F565-F573.

7. Mujais, S. K., and N. A. Kurzman. 1986. Regulation of renal Na-K-ATPase in the rat: effect of uninephrectomy. Am. J. Physiol. 251:F506-F512.

8. Zalups, R. K., B. A. Stanton, J. W. Wade, and G. Giebisch. 1985. Structural adaptation in initial collecting tubule following reduction in renal mass. Kidney Int. 27:636-642.

9. Koeppen, B. M., B. A. Biagi, and G. H. Giebisch. 1982. Intracellular microelectrode characterization of the rabbit cortical collecting duct. Am. J. Physiol. 244:F35-F47.

10. O'Neil, R. G., and S. C. Sansom. 1984. Electrophysiological properties of cellular and paracellular conductive pathways of the rabbit cortical collecting duct. J. Membr. Biol. 82:281-295.

11. O'Neil, R. G., and S. I. Helman. 1977. Transport characteristics of renal collecting tubules: influences of DOCA and diet. Am. J. Physiol. 233:F544-F558.

12. Stokes, J. B., M. J. Ingram, A. D. Williams, and D. Ingram. 1981. Heterogeneity of the rabbit collecting tubule: localization of mineralocorticoid hormone action to the cortical portion. Kidney Int. 20:340-347.

13. Muto, S., H. Furuya, K. Tabei, and Y. Asano. 1991. Site and mechanism of action of epidermal growth factor in rabbit cortical collecting duct. Am. J. Physiol. 260:F163-F169.

14. Muto, S., K. Yasoshima, K. Yoshitomi, M. Imai, and Y. Asano. 1990. Electrophysiological identification of $\alpha$ - and $\beta$-intercalated cells and their distribution along the rabbit distal nephron segments. J. Clin. Invest. 86:1829-1839.

15. Muto, S., S. Sansom, and G. Giebisch. 1987. Effects of high K diet on electrical properties of cortical collecting ducts from adrenalectomized rabbit. $J$. Clin. Invest. 81:376-380.

16. Muto, S., G. Giebisch, and S. Sansom. 1987. Effects of adrenalectomy on CCD: evidence for differential response of two cell types. Am. J. Physiol. 253:F742-F752.

17. Wade, J. B., R. G. O'Neil, J. L. Pryor, and E. L. Boulpaep. 1979. Modulation of cell membrane area in renal collecting tubules by corticosteroid hormones. J. Cell Biol. 81:439-445.

18. Mujais, S. K., M. A. Chekal, W. J. Jones, J. P. Hayslett, and A. J. Katz. 1985. Modulation of renal sodium-potassium adenosine triphosphatase by aldosterone. J. Clin. Invest. 26:170-176.

19. Garg, L. C., M. A. Knepper, and M. B. Burg. 1981. Mineralocorticoid effects on Na-K-ATPase in individual nephron egments. Am. J. Physiol. 240:F536-F544.

20. Schwartz, G. J., and M. B. Burg. 1987. Mineralocorticoid effects on cation transport by cortical collecting tubules in vitro. Am. J. Physiol. 235:F576-F585.

21. Muto, S., G. Giebisch, and S. Sansom. 1988. An acute increase of peritubular K stimulates K transport through cell pathways of CCT. Am. J. Physiol. 255:F108-F114. 
22. Burg, M. B., M. Grantham, S. Abramov, and J. Orloff. 1966. Preparation and study of fragments of single rabbit nephrons. Am. J. Physiol. 210:1293-1298.

23. Sansom, S. C., and R. G. O'Neil. 1985. Mineralocorticoid regulation of apical cell membrane $\mathrm{Na}^{+}$and $\mathrm{K}^{+}$transport of the cortical collecting duct. Am. J. Physiol. 248:F858-F868.

24. Sansom, S. C., and R. G. O'Neil. 1986. Effects of mineralocorticoids on transport properties of cortical collecting duct basolateral membrane. Am. J. Physiol. 251:F743-F757.

25. Helman, S. I., W. Nagel, and R. S. Fisher. 1977. Ouabain on active transepithelial sodium transport in frog skin. J. Gen. Physiol. 74:105-127.

26. Sansom, S. C., S. Agulian, S. Muto, V. Illig, and G. Giebisch. 1989. K activity of CCD principal cells from normal and DOCA-treated rabbits. Am. J. Physiol. 256:F136-F142.

27. Sansom, S. C., E. J. Weinman, and R. G. O'Neil. 1984. Microelectrode assessment of chloride conductive properties of cortical collecting duct. Am. $J$. Physiol. 247:F291-F302.

28. Vehaskari, V. M., and J. Herndon. 1991. Role of mineralocorticoids in adaptation of rabbit cortical collecting duct after loss of renal loss. Am. J. Physiol. 260:F793-F799.

29. El Mernissi, G., and A. Doucet. 1984. Stimulation of Na-K-ATPase in the rat collecting tubule by two diuretics: furosemide and amiloride. Am. J. Physiol. 247:F485-F490.
30. Scherzer, P., H. Wald, and M. M. Popovtzer. 1987. Enhanced glomerular filtration and $\mathrm{Na}^{+}-\mathrm{K}^{+}$-ATPase with furosemide administration. Am. J. Physiol. 252:F910-F915.

31. Kaissling, B., and B. A. Stanton. 1988. Adaptation of distal tubule and collecting duct to increased sodium delivery. I. Ultrastructure. Am. J. Physiol. 255:F1256-F1268.

32. Stanton, B. A., and B. Kaissling. 1988. Adaptation of distal tubule and collecting duct to increased Na delivery. II. $\mathrm{Na}^{+}$and $\mathrm{K}^{+}$transport. Am. J. Physiol. 255:F1269-F1275.

33. Zalups, R. K. 1989. Effects of dietary $\mathrm{K}^{+}$and $75 \%$ nephrectomy on the morphology of principal cells in CCDs. Am. J. Physiol. 256:F387-F396.

34. Hené, R. J., P. Boer, H. A. Koomans, and E. J. Dorhout Mees. 1982. Plasma aldosterone concentrations in chronic renal disease. Kidney Int. 21:98101.

35. Garg, L., and N. Narang. 1985. Renal adaptation to potassium in the adrenaloctomized rabbit. Role of distal tubular sodium-potassium adenosine triphosphatase. J. Clin. Invest. 76:1065-1070.

36. Stanton, B., L. Pan, H. Deetjen, V. Guckian, and G. Giebisch. 1987. Independent effects of aldosterone and potassium on induction of potassium adaptation in rat kidney. J. Clin. Invest. 79:198-206.

37. Wingo, C. S., D. W. Seldin, J. P. Kokko, and H. R. Jacobson. 1982. Dietary modulation of active potassium secretion in the cortical collecting tubule of adrenalectomized rabbits. J. Clin. Invest. 70:579-586. 